\title{
The Thrill of Victory and the Agony of Defeat: Spontaneous Expressions of Medal Winners of the 2004 Athens Olympic Games
}

\author{
David Matsumoto \\ San Francisco State University
}

\author{
Bob Willingham \\ The World of Judo Magazine
}

\begin{abstract}
Facial behaviors of medal winners of the judo competition at the 2004 Athens Olympic Games were coded with P. Ekman and W. V. Friesen's (1978) Facial Affect Coding System (FACS) and interpreted using their Emotion FACS dictionary. Winners' spontaneous expressions were captured immediately when they completed medal matches, when they received their medal from a dignitary, and when they posed on the podium. The 84 athletes who contributed expressions came from 35 countries. The findings strongly supported the notion that expressions occur in relation to emotionally evocative contexts in people of all cultures, that these expressions correspond to the facial expressions of emotion considered to be universal, that expressions provide information that can reliably differentiate the antecedent situations that produced them, and that expressions that occur without inhibition are different than those that occur in social and interactive settings.
\end{abstract}

Keywords: emotion, facial expressions, Olympic Games, universality, FACS

Since Darwin's (1872/1998) classic work, the nature and function of facial expressions of emotion have long been a topic of interest and debate. They are universally recognized (Elfenbein \& Ambady, 2002; Matsumoto, 2001; but see critiques by Russell, 1991, 1994, and rejoinders by Ekman, 1994; Izard, 1994), are displayed by congenitally blind infants and children (Charlesworth \& Kreutzer, 1973) and nonhuman primates (Chevalier-Skolnikoff, 1973; Geen, 1992; Hauser, 1993; Snowdon, 2003), are associated with distinct physiological signatures (Davidson, 2003; Ekman, Levenson, \& Friesen, 1983; Levenson, Ekman, \& Friesen, 1990, Levenson, Ekman, Heider, \& Friesen, 1992; Tsai \& Levenson, 1997), and correspond to emotion taxonomies around the world (Romney, Moore, \& Rusch, 1997; Shaver, Murdaya, \& Fraley, 2001; Shaver, Schwartz, Kirson, \& O'Connor, 1987). However, questions exist concerning whether or not spontaneous expressions of emotion occur in real-life, naturalistic settings. We contribute to this literature by reporting on our examination of emotional expressions of athletes at the 2004 Athens Olympic Games in three very different but highly charged emotional contexts to address basic questions about the nature of spontaneous facial expressions of emotion.

David Matsumoto, Department of Psychology, San Francisco State University; Bob Willingham, The World of Judo Magazine, Bristol, England.

We thank Yasuko Sato for FACS coding the expressions; Robert Levenson for his assistance in producing the EMFACS predictions; Paul Ekman for his review of the EMFACS predictions and comments on a draft of this article; Satoko Hirayama, Ana Maria Anguas Wong, Natalia Kouznetsova, Yasuko Sato, and Seung Hee Yoo for their comments on a draft of this article; and Akiko Terao, Marija Drezgic, Andres Olide, Devon McCabe, and Sanae Nakagawa for their assistance in the general laboratory program.

Correspondence concerning this article should be addressed to David Matsumoto, Department of Psychology, San Francisco State University, 1600 Holloway Avenue, San Francisco, CA 94132. E-mail: dm@sfsu.edu
The Link Between Emotionally Evocative Contexts and Facial Expressions of Emotion

Laboratory studies have demonstrated that emotionally evocative stimuli reliably elicit discrete facial expressions of emotion when there is no reason for participants to manage or modify their expressions (Berenbaum \& Oltmanns, 1992; Bonanno \& Keltner, 2004; Camras, Oster, Campos, Miyake, \& Bradshaw, 1992; Chesney, Ekman, Friesen, Black, \& Hecker, 1990; Ekman, 1972; Ekman, Davidson, \& Friesen, 1990; Ekman, Friesen, \& Ancoli, 1980; Ekman, Friesen, \& O’Sullivan, 1988; Ekman, Matsumoto, \& Friesen, 1997; Ellgring, 1986; Frank, Ekman, \& Friesen, 1993; Gosselin, Kirouac, \& Dore, 1995; Heller \& Haynal, 1994; Keltner, Moffitt, \& Stouthamer-Loeber, 1995; Keltner \& Bonanno, 1997; Rosenberg \& Ekman, 1994; Ruch, 1993, 1995). Field studies, however, suggest otherwise. In Kraut and Johnson's (1979) Studies 1 and 2, bowlers smiled less when facing the pins and watching the action compared with when they faced their companions. In Study 3, smiles occurred when something favorable to the home team had happened, and when fans were socially involved with one another. In Study 4, pedestrians smiled more on nice days than on bad days, and if they were in social interaction with someone else than not. In Ruiz-Belda, Fernandez-Dols, Carrera, and Barchard's (2003) Study 1, bowlers smiled more when turned to the pit (and presumably in social interaction), and not when they were facing the pins. In their Study 2, soccer fans smiled more frequently when they interacted with another fan, but not when watching the action on television. Finally Fernandez-Dols and Ruiz-Belda (1995) reported that Duchenne smiles occurred most frequently and for the longest duration when athletes from the 1992 Barcelona Olympic Games interacted with dignitaries to get their medal, but not when standing behind the podium or listening to the anthem.

These reports of nonfindings are commensurate with Fridlund's (1994, 2002) behavioral ecology view of expressions, which posits that facial expressions do not reflect underlying emotional states 
per se but instead are displays of intent aimed at controlling "the trajectory of a given social interaction" (Fridlund, 1994, p. 130). In this view, facial expressions serve social motives that are mostly determined by the presence of a true or internalized audience, and any link between facial expression and emotion is a circumstantial by-product of the concurrence between social motives and some emotions.

\section{Methodological Considerations}

Although arguments about the meaning of facial expressions of emotion and their relationship with emotion-eliciting situations have peppered the literature (Ekman, 1992, 1999, 2003; Fridlund, 1997; Keltner, Ekman, Gonzaga, \& Beer, 2003; Russell, Bachorowski, \& Fernandez-Dols, 2003; Russell \& Fernandez-Dols, 1997), the field is relatively short on rigorous expressive data to address these issues. Laboratory experiments typically lack the investigation of expression in social situations with other interactants ${ }^{1}$ and in many cases involve unnatural emotion elicitation techniques created for the purpose of studying emotion in the laboratory, an unnatural situation itself. Studies of expressive behavior outside the laboratory are important, not only because they address theoretical questions in real life but also because they describe behavior in their richness and complexity (Goffman, 1959). The conclusions from the field studies cited earlier, however, were premature because of limitations in their methodologies, some discussed elsewhere (Bonanno \& Keltner, 2004). Here we focus on three directly relevant to our study.

\section{Strong Elicitation of Emotion}

When studying emotion, it is imperative that emotion be elicited strongly enough to be studied. It is questionable as to whether this occurred in the three field reports cited earlier. For instance, the assumption in the studies involving bowlers (Kraut \& Johnson, 1979; Ruiz-Belda et al., 2003) is that they should feel and express happiness each and every time they bowl a spare or a strike. Spares and strikes are good, but whether they need to be antecedents to happiness each and every time in a game is questionable. Many athletes in the middle of competition or individuals in the middle of a task keep their emotions in check pending the final outcome (Kerr, Wilson, \& Nakamura, 2005). Emotions are not akin to physical reactions; the same antecedent that brings about an emotion once is likely not to bring about that same emotion again even though the same antecedents repeatedly occur (Ekman, Friesen, \& Simons, 1985).

\section{Allowing Time for Expressions to Unfold}

The time frame analyzed has to be long enough for expressions to unfold. This may not have been the case in the field studies described earlier. For instance, in Ruiz-Belda and colleagues' (2003) study, the time frame for expressions to be observed in bowlers facing the pins was $1.35 \mathrm{~s}$. Assuming that a second is required for the ball to go through the pins and the final result to occur, that leaves about $0.35 \mathrm{~s}$ for sensation, perception, appraisal, emotion elicitation, innervation of the facial nerve, and facial muscle movement to onset and reach apex. Given that the bowlers immediately turned to the pit, their expressions may have occurred while they were turning toward the pit. If so, then it makes sense that they would smile much more while facing the pit because of the short amount of time recorded while facing the pins. That the amount of time facial behavior was recorded in interaction was $2.83 \mathrm{~s}$ supports this notion, if the average time window of an expression unfolding (about $4 \mathrm{~s}$ ) is considered (Ekman, 2003). Ruiz-Belda and colleagues (2003) attempted to remedy this time differential by examining facial behaviors during the first $1.35 \mathrm{~s}$ of the second, interactive phase. However, this procedure does not correct for the fact that the first time window is too short; the better procedure would have been for the first time window to be long enough to allow expressions to occur if they were going to. ${ }^{2}$

\section{Measuring Expressions in Precise, Moment-to-Moment Fashion}

The face is one of the most complex signal systems available to humans, and facial expressions can be fleeting, rich, and incredibly varied. Observer judgments cannot capture the richness and variety of the face. For example Kraut and Johnson (1979) never distinguished between Duchenne smiles and non-Duchenne smiles. Duchenne smiles involve both the zygomatic major (which pulls the lip corners up) and the orbicularis oculi (the muscle surrounding the eyes); they have been associated with enjoyment (Ekman et al., 1990; Frank \& Ekman, 1993; Soussignan, 2002). NonDuchenne smiles do not involve orbicularis oculi and occur when people smile to be pleasant or because of social circumstance, even though they may not feel positive emotion. It may have been possible, therefore, that the individuals in Kraut and Johnson's study produced more non-Duchenne smiles in the social interaction conditions. Although Ruiz-Belda and colleagues (2003) scored the facial behavior with the Facial Affect Coding System (FACS; Ekman \& Friesen, 1978), they did not differentiate among Duchenne and non-Duchenne smiles, either.

\section{The Current Study}

The purpose of this study was to investigate expressive behavior in a naturalistic setting while addressing the methodological issues described earlier. We examined the spontaneous facial expressions of athletes immediately after they had just won or lost a medal

\footnotetext{
${ }^{1}$ Ekman's (1972) study is a notable exception. Studies of expressive behavior in marital interactions are also notable exceptions (Ekman, 2003).

2 The same is true for their study of soccer fans. The mean duration of the noninteractive phases was just $2.0 \mathrm{~s}$, whereas the mean duration for the interactive phases was $7.2 \mathrm{~s}$. If expressions of spontaneous emotion generally last on the face between 0.5 and $4 \mathrm{~s}$ after emotion is aroused, then the $2.0 \mathrm{~s}$ time frame for the noninteractive phase is just too short to fairly determine whether expressions will occur or not, given that emotion was aroused. Again, Ruiz-Belda and colleagues (2003) attempted to rectify this discrepancy by analyzing facial data from only the first $2 \mathrm{~s}$ of the interactive phase and demonstrated that smiles occurred more readily there anyway. However, if the timing of expression dynamics vis-à-vis emotion arousal is considered, it would be expected that expressions occur precisely during that time frame, which would be within $4 \mathrm{~s}$ of the beginning of the emotional episode. That Ruiz-Belda and colleagues reported a high prevalence of smiling during this time frame, therefore, may actually be evidence in favor of the notion that smiles are natural expressions of the presence of happiness.
} 
match at the 2004 Athens Olympic Games judo competition. A judo match lasts for $5 \mathrm{~min}$ and starts with two contestants in a standing position vying for a grip on each other. There are throwing techniques that originate from standing, and there are grappling techniques on the ground. Points are awarded by throwing the opponent to the ground on the back or by applying a pin, choke, or armlock. Instant wins (the equivalent of a knockout in boxing) are awarded for clean throws to the back, pinning the opponent on the ground for $25 \mathrm{~s}$, or when an opponent submits because of a choke or armlock. Because instant wins can occur at any time during a match, the outcome of a match is never decided until the end of competition time or when an instant win occurs. Athletes participate in a tournament system requiring them to compete in many matches in a single day; thus judo competition at the Olympic Games requires tremendous strength and conditioning. Because the Olympic Games occur only once every 4 years, winning or losing a medal here is one of the most powerful emotional experiences in the lives of these athletes. ${ }^{3}$ The expressions were photographed by a high-speed digital camera and measured in precise, moment-to-moment fashion using FACS coding (Ekman \& Friesen, 1978), continuously from immediately after match completion until the winner was awarded the match-approximately 10 to $15 \mathrm{~s}$ - to allow for expressions to unfold. We coded all facial behaviors, not just smiles, to examine a range of expressions. Moreover, we examined the spontaneous expressions of the same athletes at two times during the medal ceremonies, once when interacting with a dignitary when receiving a medal, the second time on the podium posing. Contrasting expressions that occurred immediately at match completion in the heat of battle with those that occurred during the medal ceremonies allowed us to examine expressive behavior in different contexts, one of which was clearly more social and public.

\section{Theoretical Questions}

\section{Do Expressions Occur in Emotionally Evocative Situations?}

The main question addressed by our data concerns whether or not expressions occur at all in emotionally evocative situations. We contend that they do, provided the situations are highly charged, sufficient time is allotted to examine whether expressions occur, and expressions are measured with moment-to-moment precision.

\section{The Expression of Victory}

Sport competition, like many achievement situations, elicits many emotions, especially related to success and failure. One of the most salient emotions for the winners is that of enjoyment. There are many different types of enjoyable emotions; Ekman (2003) distinguished among 16: five sensory pleasures, amusement, contentment, excitement, relief, wonder and awe, ecstasy and bliss, fiero (good feelings about oneself at the moment of accomplishment), elevation, gratitude, schadenfreude (joy in another's misfortune), and naches (pride-pleasure in the achievement of one's children). Shaver's (Shaver et al., 1987, 2001) work on the emotion lexicon grouped positive emotions into two categories: love, with three subcategories (adoration, arousal, and longing), and happiness with five (amusement, enthusiasm, contentment, enthrallment, and relief).

Ekman (2003) suggested that all enjoyment emotions are signaled in the face by Duchenne smiles. Many studies have shown, in fact, that Duchenne smiles are related to enjoyment and amusement (Frank et al., 1993; Hess, Banse, \& Kappas, 1995; Keltner, 1995; Keltner \& Bonanno, 1997; Smith, 1995). To date, however, no study has examined the facial signals of enjoyment related to achievement and accomplishment. Our study does so.

\section{The Expression of Defeat}

What about athletes who lose their medal matches? Of course winning any medal in Olympic competition is an amazing accomplishment. Folk beliefs suggest a linear decrease in positive emotions, with the gold medalists experiencing the most, followed by the silver medalists, and then bronze. However, in reality, the silver medalist loses the gold medal match, and the bronze medalists win their last match, capturing the bronze and avoiding going home without a medal. Medvec, Madey, and Gilovich (1995) showed that bronze medalists from the 1992 Barcelona Games appeared happier than silver medalists at the end of the match and on the podium, and that silver medalists' comments were much more characterized by counterfactual thinking about "what might have been" and were associated with greater regret and less enjoyable emotion.

What is the expression associated with defeat? It may simply be the case that athletes who lose their medal match-silver medalists and fifth placers - are less happy and thus smile less or differently; they may show nothing, neutralizing their expressions to be a good loser; or they may show other emotions. No study has examined these possibilities. In this study, we do so by examining the facial behaviors of the athletes who lose their medal match-silver medalists and fifth placers.

\section{The Timing of Expressions}

Spontaneous emotional expressions last between 0.5 and $4 \mathrm{~s}$ on the face (Ekman \& Friesen, 1982b; Frank et al., 1993; Hess \& Kleck, 1990; Leonard, Voeller, \& Kudau, 1991; Richardson, Bowers, Bauer, Heilman, \& Leonard, 2000). We do not know, however, how much time is needed from the occurrence of an emotioneliciting stimulus to the beginning of its expressive reaction. Facial reactions to startling stimuli occur within $100 \mathrm{~ms}$ of stimulus occurrence (Ekman et al., 1985). However, startles are reflexes, not emotions, and probably bypass the emotion appraisal process. In the solitary emotion-elicitation condition of Schmidt, Cohn, and Tian's (2003) study, the time from stimulus occurrence to the beginning of its expressive reaction was $2.4 \mathrm{~s}$. Ruiz-Belda et al.'s (2003) data also showed that expressions generally occurred after $2 \mathrm{~s}$ but within $4 \mathrm{~s}$ of stimulus occurrence. Schmidt and colleagues,

\footnotetext{
${ }^{3}$ We do not bring an uninformed background to this topic. David Matsumoto is a 6th-degree black belt in judo, team leader for the U.S Olympic Judo Team in Atlanta (1996), director of international coaching and training for the U.S. judo team in Sydney (2000), and a technical official of the International Judo Federation in Athens (2004). Bob Willingham is a 4th-degree black belt in judo, former All England heavyweight champion, and former member of the British national judo squad.
} 
however, did not analyze their onset data systematically. This study contributes to this literature by directly measuring the time from stimulus occurrence (match ending) to the beginning of expression onset. Understanding this aspect of expression timing has implications for our theoretical understanding of emotion.

\section{Expressive Differences as a Function of Social Situation}

There have been only a couple of studies that have examined expression differences in different contexts in the same individuals in a within-subjects design. Ekman (1972) demonstrated that, although Americans and Japanese both showed their displays of disgust, anger, fear, and sadness while alone, more Japanese smiled to mask their negative feelings when viewing the stimuli in the presence of a higher status experimenter. Ekman and Friesen (1969) coined the term cultural display rules to explain such expressive differences. Matsumoto and Kupperbusch (2001) extended these findings by demonstrating that collectivistic participants deamplified expressions of both positive and negative feelings when with the higher status experimenter.

How might expressive behavior be different in the current study? We expected that all athletes regardless of place finish would spontaneously engage in smiling behavior during the medal ceremonies because of the very social nature of the event. Yet the specific types of smiles for silver medalists should be different than for the gold or bronze medalists, congruent with the findings of Medvec et al. (1995). We did not know exactly how, however, their smiles would differ, because expressive data from individuals in comparable situations do not exist. The data from the current study should allow us to examine whether all athletes do engage in smiling and whether the silver medalists' smiles are different from those of the gold or bronze medalists.

\section{Method}

\section{The Setting}

The staging of the judo competition at the Olympic Games provided the perfect controlled environment for a naturalistic, field study. Judo competition was held at the Ano Liossia Competition Hall in Athens, Greece, which has a seating capacity of 8,000 . In the stadium there were two competition areas in the field of play, both on an elevated platform. Each competition area consisted of an $8 \times 8 \mathrm{~m}$ contest area, with a 3-m safety area bordering three of the outside edges and a 4-m safety area in between the common edges of the contest areas. A large runway ran around the entire competition areas for athlete and staff entrances and exits on one side and for all technical officials on the other three sides. ${ }^{4}$ The main spectator seating areas were along three of the sides of the competition area; the fourth side was reserved for VIPs and broadcast companies. The main television cameras were situated on the side of the spectators in between the competition areas. Bob Willingham, who is a professional photographer and the official photographer of the International Judo Federation, was situated in between both competition areas on the side of the technical officials, that is, opposite the main spectator seating and the main television cameras. Thus it was impossible for the photographer to obtain expressions when the athletes faced the crowd.

There are seven weight categories each for men and women, and competition occurred for 7 days; each day one weight category for both sexes was contested. Competition occurs in a standard elimination system where winners proceed through preliminary rounds and then quarter-, semi-, and final rounds. Athletes who lose to the semifinalists are placed in a loser's bracket (known as the repechage) and compete in an elimination system. The gold medalist is the athlete who wins the final round (thus not having lost any matches); the silver medalist is the loser of the final round. Bronze medals are awarded to the winners of the match between the winner of the repechage and the loser of the semifinals; because there are two semifinals and two repechages, two bronze medals are awarded.

Preliminary rounds started every morning at 10:30 a.m., and ended by 2 p.m. At 4:30 p.m. the semifinal, repechage finals, bronze medal matches, and then gold medal matches were contested for both men and women. During the preliminary, semifinals, repechage finals, and bronze medal matches, contests occurred on both competition areas; thus the photographer (Bob Willingham) took shots on both mats, alternating between one and the other, depending on the action and the athletes competing. Final, gold medal matches, however, occurred one at a time; thus the photographer was able to focus all attention on those matches.

The photographer took action shots during the contests. For the purposes of this study, however, the photographer was instructed to also take shots of the athletes after match completion. Matches can end in one of five ways: time running out; an athlete is thrown cleanly with speed, force, and control, onto his or her back; an athlete pins the opponent to the ground for $25 \mathrm{~s}$; an athlete submits because of the effects of a choke; or an athlete submits because of the effects of an armlock. Photographs were taken of the athletes after match completion until the match was awarded by the referee, a time period that generally occurred within $15 \mathrm{~s}$. The photographer was told that the focus of the study was on expressions; however, no information was given about what specific type of expression or channel, no mention was made of emotion, and he had no formal training in psychology nor knew the literature related to the study or the specific hypotheses to be tested.

Medal ceremonies occurred in the middle of the competition area, and generally about $30 \mathrm{~min}$ after the completion of the last match of the day. Athletes were marched in single file, stood behind the podium, stood up onto the podium when their names were called, and received their medal and wreath from a dignitary. After all athletes had received their medals, they stood for the playing of the national anthem of the gold medalist and then gathered on the gold medal podium for a group photo. They then marched around all four sides of the field of play, stopping to greet fans and allow their photos to be taken.

\section{Photographic Equipment}

The camera used was a Nikon D2H professional digital camera. It has a high frames-per-second rate ( 8 frames per second, with $37-$ ms shutter time lag) and high resolution (4.1 megapixels effective). The camera was set to use auto focus and manual exposure using available light and shooting in JPEG file formats. The International Standards Organization range used was between 400 and 800, giving shutter speeds of around 1/500th of a second. A variety of interchangeable Nikkor lenses were used, including 28-70 f2.8, 70-200 f2.8, and 300-mm f2.8.

\section{Photo Selection}

For the purposes of this study we selected photos from the bronze and gold medal matches. Although winning or losing any match can be an antecedent for joy or distress, we wanted to use situations that were clearly the most emotionally charged. These are the medal matches. When a medal match is completed, athletes are done with their Olympic competition, and the final outcome of their performance is determined. For many, it is the end of their competitive career. Although athletes compete in, win and lose, many matches throughout their career, competing in a medal round in the

\footnotetext{
${ }^{4}$ In the Olympic Games, the field of play is a highly secure area, and only individuals with a certain security credential are allowed onto the field.
} 
Olympics is a once-in-a-lifetime experience. It is likely to elicit strong emotions, determining whether an athlete gets a medal or not (losers of the bronze medal matches do not get a medal) or wins the gold or not. Given the finality and rarity of the situation, it is highly likely that medal match completion, therefore, will be associated with strong emotions for both winners and losers.

An additional merit to the focus on medal matches is the fact that the medalists participated in the medal ceremony. Whereas the medal matches are likely to lead to relatively uninhibited expressions because of the nature of the situation and competition (more on this later), the medal ceremonies are clearly a social event, produced for the purpose of a viewing audience both in the arena and on television. By focusing on the athletes in the medal matches, we had a chance to observe and measure their spontaneous behavior in two very different situations. This is not true, however, for all other athletes who are eliminated in the preliminary rounds.

Approximately 3,000 shots were taken from each day's competition, resulting in about 21,000 photographs across the 7 days of competition. Of these, we examined all shots taken immediately at the end of each medal match, from the precise moment in time when the match was over and the outcome was known to the time the decision was announced by the referee, a span of approximately 10 to $15 \mathrm{~s}$. Shots were also examined at two times during the medal ceremonies-when the athlete received the medal from the dignitary and when the four athletes were on the gold medal stand posing. Across the 7 days of competition, this resulted in a preliminary selection of 2,735 shots.

Because this study focused on facial behavior, photos were then selected for detailed FACS coding. Photos were selected if there was at least a clear profile view of the face of the athlete and if any facial muscles were contracted. When an expression was on a face, we examined the series of photographs that depicted the beginning of the expression to its end. We selected photographs in which expressions had reached their apex for detailed FACS coding. If an expression was already on a face, a new expression was determined to exist if different facial muscles were contracted or existing facial muscles changed by at least two intensity levels according to FACS coding (Ekman \& Friesen, 1978). This resulted in the selection of 190 photographs, 117 from the medal matches and 73 from the medal ceremonies. ${ }^{5}$

\section{Athlete Participants Whose Expressions Were Measured}

The individuals who contributed expressions in this study, therefore, were the 84 gold, silver, bronze, and fifth place winners of the judo competition at the 2004 Athens Olympic Games. They represented 35 different countries around the world from six continents. As such, they constituted a sample of the most culturally diverse individuals in whom spontaneous expressions that occurred in a highly charged, emotional event in three situations-immediately at the end of match completion and two times in the medal ceremonies-have been examined.

\section{Expression Coding and Emotion Predictions}

All selected expressions were coded using Ekman and Friesen's (1978) FACS. FACS identifies each of the functionally anatomical facial muscle movements (action units; AUs) that can occur independently, as well as head and eye positions. All expressions were coded by two certified FACS coders (one was David Matsumoto; the other was blind to the hypotheses and goals of the study); interrater reliability, calculated by doubling the number of codes on which coders agreed and dividing by the total number of codes used, was .79.

All AU combinations were then compared with the Emotion FACS (EMFACS) dictionary to obtain emotion predictions (Ekman \& Friesen, 1982a; Matsumoto, Ekman, \& Fridlund, 1991). The dictionary was accessed via a computer program available to all researchers who have FACS data (Levenson, 2005). EMFACS identifies AUs that are theoretically related to facial expressions of emotion posited by Darwin (1872/1998) and later Tomkins $(1962,1963)$ and empirically verified by studies of spontaneous expression and judgments of expressions by Ekman and colleagues over 20 years (Ekman et al., 1990; Ekman \& Friesen, 1971; Ekman et al., 1980; Ekman, Friesen, \& Ellsworth, 1972; Ekman et al., 1988; Ekman, Sorenson, \& Friesen, 1969). The facial configurations associated with the emotion predictions were first listed in Ekman (1972) and in the original FACS manual (Ekman \& Friesen, 1978). Prototypic examples of the emotion facial configurations were described in Ekman and Friesen's (1975) Unmasking the Face and portrayed in their Pictures of Facial Affect (Ekman \& Friesen, 1976) and the Japanese and Caucasian Facial Expressions of Emotion (Matsumoto \& Ekman, 1988) sets. The EMFACS dictionary has been used in many published studies (Berenbaum \& Oltmanns, 1992; Ekman et al., 1990, 1997; Keltner et al., 1995; Matsumoto, Haan, Gary, Theodorou, \& Cooke-Carney, 1986; Rosenberg \& Ekman, 1994; Rosenberg, Ekman, \& Blumenthal, 1998, Rosenberg et al., 2001; SteimerKrause, Krause, \& Wagner, 1990), as well as in studies that used FACS and then virtually the same dictionary codes to produce emotion predictions but did not mention EMFACS (Chesney et al., 1990; Ekman et al., 1988; Frank et al., 1993; Gosselin et al., 1995; Heller \& Haynal, 1994; Keltner, 1995; Levenson, Carstensen, Friesen, \& Ekman, 1991; Messinger, Fogel, \& Dickson, 2001; Ruch, 1993, 1995; Sayette et al., 2003). The results of many of these more recent studies were used to adjust the EMFACS emotion predictions. The predictions were then reviewed by Paul Ekman, who was blind to the condition (match vs. medal, winner vs. loser) from which the AUs were generated. Ekman checked all predictions and provided updated predictions based on later findings between faceemotion relationships that had not been updated in the EMFACS dictionary. In actuality, these resulted in only 10 updates of 230 expressions.

\section{Results}

\section{Did Expressions Occur at Match Completion?}

Of the 84 athletes, there were no usable photos for $6 .{ }^{6}$ Of the remaining 78, $67(86 \%)$ provided at least one expression that was FACS codable. Of these, $33(49 \%)$ provided 2 expressions, 13 (19\%) provided 3 , and $5(7 \%)$ provided 4 . Of the 118 expressions coded, only 5 did not produce an emotion prediction by the EMFACS dictionary (see Table 1). Thus, the vast majority of the athletes produced expressions at match completion, and these corresponded to emotions predicted by EMFACS. (A complete listing of all FACS codes used and their emotion predictions is available from David Matsumoto.)

Recall that it was impossible for us to obtain expressions when athletes were facing the crowd. To examine whether the athletes were facing others when they produced their expressions, we coded whether or not the athlete was directly facing anyonecrowd, opponent, referee-when the expression was captured. Seventy-two percent of the first expressions occurred when the athletes were not facing anyone.

\footnotetext{
${ }^{5}$ The number of predictions is larger than the number of photographs selected because the final podium shots were photographs that involved expressions by all four medalists in a single shot.

${ }^{6}$ One bronze medal match did not occur because of injury to 1 of the athletes. Another bronze medal match ended quickly, and the photographer was focused on the other simultaneously occurring bronze medal match. And for two gold medal matches there was no usable photo for the silver medalist.
} 
Table 1

Raw Frequencies of Athletes Displaying Various Expressions at Match Completion and During Medal Ceremonies

\begin{tabular}{|c|c|c|c|c|c|}
\hline Occasion & Type of expression & Gold & Silver & Bronze & Fifth \\
\hline \multirow[t]{14}{*}{ Match completion } & Smiles & & & & \\
\hline & Duchenne smiles by themselves & 2 & 0 & 1 & 0 \\
\hline & Duchenne smiles with open mouth & 10 & 0 & 14 & 1 \\
\hline & Duchenne smiles with sadness & 0 & 0 & 2 & 0 \\
\hline & Other smiling & 1 & 0 & 1 & 0 \\
\hline & Contempt & 0 & 2 & 1 & 4 \\
\hline & Disgust & 0 & 0 & 0 & 1 \\
\hline & Fear & 0 & 0 & 0 & 1 \\
\hline & Sadness & 0 & 6 & 5 & 9 \\
\hline & Undifferentiated negative & 0 & 0 & 0 & 1 \\
\hline & No prediction & 1 & 0 & 1 & 3 \\
\hline & No expression & 0 & 4 & 1 & 6 \\
\hline & No usable photo & 0 & 2 & 2 & 2 \\
\hline & Total & 14 & 14 & 28 & 28 \\
\hline \multirow[t]{10}{*}{ Receipt of medal } & Smiles & & & & \\
\hline & Duchenne smiles by themselves & 2 & 3 & 3 & \\
\hline & Duchenne smiles with open mouth & 12 & 3 & 20 & \\
\hline & Duchenne smiles with control & 0 & 3 & 3 & \\
\hline & Non-Duchenne smile & 0 & 1 & 0 & \\
\hline & Non-Duchenne smiles with control & 0 & 1 & 1 & \\
\hline & Smile-sadness blends & 0 & 2 & 0 & \\
\hline & Contempt & 0 & 0 & 1 & \\
\hline & No expression & 0 & 1 & 0 & \\
\hline & Total & 14 & 14 & 28 & \\
\hline \multirow[t]{11}{*}{ Podium posing } & Smiles & & & & \\
\hline & Duchenne smiles by themselves & 3 & 4 & 2 & \\
\hline & Duchenne smiles with open mouth & 9 & 1 & 13 & \\
\hline & Duchenne smiles with control & 1 & 3 & 6 & \\
\hline & Non-Duchenne smile & 1 & 1 & 1 & \\
\hline & Non-Duchenne smiles with control & 0 & 0 & 4 & \\
\hline & Smile-sadness blends & 0 & 1 & 0 & \\
\hline & Contempt & 0 & 1 & 0 & \\
\hline & Sadness & 0 & 2 & 0 & \\
\hline & No prediction & 0 & 1 & 2 & \\
\hline & Total & 14 & 14 & 28 & \\
\hline
\end{tabular}

All analyses involving match completion presented subsequently used only the first expression displayed by each athlete, to avoid problems of independence of the data.

\section{The Expression of Victory}

Thirteen of the 14 gold medalists and 18 of 26 bronze medalists (2 had unusable photos) smiled (binomial test with chance set conservatively at 50\% here and later, $z=2.67, p<.01$, and $z=$ 1.96, $p<.05$, respectively; see Table 1 ). Of these 31 smiles, 29 were Duchenne smiles, and 24 of these were open mouth. These results provide support for the notion that the Duchenne smile is a signal of enjoyment, replicating previous studies (Frank et al., 1993; Hess et al., 1995; Keltner \& Bonanno, 1997; Smith, 1995).

\section{The Expressions of Defeat}

None of the silver medalists, and only 1 of the 26 fifth placers, smiled $(z=-3.74, p<.0001$, and $z=4.71, p<.00001$, respectively; see Table 1). There was not a unique expression of defeat; most athletes displayed sadness (43\% and 35\%), nothing (29\% and $23 \%$ ), or contempt (14\% and $15 \%$ for silver medalists and fifth placers, respectively). It is possible that the 10 athletes who showed nothing expressed shame in other, nonfacial cues, and future studies examining nonfacial, nonverbal behaviors can investigate this possibility.

The difference between the facial behaviors of the victors (gold and bronze medalists) and defeated athletes (silver medalists and fifth placers) was striking (see Table 2, top). The victors were much more likely to smile, especially to display Duchenne smiles; the losers were much more likely to display negative emotions or nothing. These findings are directly in line with those of Medvec et al. (1995), who showed that the 1992 Barcelona Olympic silver medalists were judged less happy than bronze medalists at match completion. Moreover it is not the case that the silver medalists (and fifth placers) are just less happy; those who displayed something displayed discrete, negative emotions.

We then examined whether the distribution of expressions differed according to culture. Because of small sample sizes for individual countries, we combined them into three categories: North America-Western Europe (Australia, Austria, Belgium, Canada, Spain, France, Great Britain, Germany, Greece, Israel, Italy, The Netherlands, the United States), East Asia (China, Japan, South Korea, Mongolia, North Korea), and all others (Algeria, Argentina, Azerbaijan, Belarus, Brazil, Bulgaria, Cuba, Estonia, 
Table 2

Cross-Tabulations of Type of Expression Based on Emotion Facial Action Coding System Predictions at Three Different Points in Time: Match Completion, Receiving Medal, and On the Podium

\begin{tabular}{|c|c|c|c|c|c|c|c|}
\hline Occasion & Type of expressions & $\begin{array}{c}\text { Gold } \\
\text { and } \\
\text { bronze }\end{array}$ & $\begin{array}{c}\text { Silver } \\
\text { and fifth }\end{array}$ & $x^{2}$ & $d f$ & $p$ & $r$ \\
\hline \multirow[t]{6}{*}{ Match completion } & Any smiling (AU 12) & 31 & 1 & 45.43 & 1 & .00 & .74 \\
\hline & All other expressions & 11 & 41 & & & & \\
\hline & Duchenne smiles & 29 & 1 & 40.65 & 1 & .00 & .70 \\
\hline & All other expressions & 13 & 41 & & & & \\
\hline & Negative emotions or no expressions & 6 & 34 & 37.42 & 1 & $<.001$ & .67 \\
\hline & All other expressions & 36 & 8 & & & & \\
\hline \multirow[t]{5}{*}{ Receipt of medal } & All Duchenne smiles & 40 & 9 & 9.20 & 1 & .0024 & .41 \\
\hline & All other expressions & 2 & 5 & & & & \\
\hline & All uncontrolled & & & & & & \\
\hline & Duchenne smiles & 37 & 6 & 12.06 & 1 & .0005 & .46 \\
\hline & All other expressions & 5 & 8 & & & & \\
\hline \multirow[t]{6}{*}{ Podium posing } & All Duchenne smiles & 34 & 8 & 3.18 & 1 & .0747 & .24 \\
\hline & All other expressions & 8 & 6 & & & & \\
\hline & $\begin{array}{l}\text { All uncontrolled } \\
\text { Duchenne smiles }\end{array}$ & 27 & 5 & 3.5 & 1 & .0613 & .25 \\
\hline & All other expressions & 15 & 9 & & & & \\
\hline & $\begin{array}{l}\text { Negative emotion or uninterpretable } \\
\text { expressions }\end{array}$ & 2 & 5 & 9.20 & 1 & $<.01$ & .41 \\
\hline & All other expressions & 40 & 9 & & & & \\
\hline
\end{tabular}

Note. $\quad \mathrm{AU}=$ action unit.

Georgia, Iran, Moldova, Poland, Romania, Russia, Slovenia, Tunisia, Ukraine). This gross classification separated North America-Western Europe from East Asia on a number of cultural dimensions, including Hofstede's (2001) Individualism versus Collectivism, Power Distance, and Long versus Short Term Orientation, and Schwartz's (2004) Affective and Intellectual Autonomy, Egalitarianism, Embeddedness, and Hierarchy, with the other countries occupying a more intermediate position.

We computed three chi-square values, one for each three-way contingency table of the match completion data in the top of Table 2, using type of expression, place finish (gold and bronze vs. silver and fifth), and culture (three categories mentioned earlier) as independent variables. None were significant: smiling versus all other expressions, $\chi^{2}(4, N=84)=0.70, n s$; Duchenne smiles versus all other expressions, $\chi^{2}(4, N=84)=0.37, n s$; negative emotions or no expressions versus all other expressions, $\chi^{2}(4, N=$ $84)=0.23, n s$, indicating that there were no cultural differences in expression at match completion.

\section{How Much Time Elapsed From the Occurrence of an Emotion-Eliciting Stimulus to Its Expressive Reaction?}

The photographic equipment date and time stamped each photograph (to the second), along with information about technical settings. We calculated the time that elapsed after each match ended to the onset of the expression that was FACS coded, from onset to apex (which was FACS coded), and the total time from end of match to apex (see Table 3). The relevant data are for the gold and bronze medalists; the data for the silver medalists and fifth placers are not valid markers of expression timing because the photographer captured the expressive behavior of the victors first (common in sport photography) and then the defeated athletes after that.

The mean time from match completion to expression onset was $2.90 \mathrm{~s}$ and $2.57 \mathrm{~s}$ for the gold and bronze medalists; from match completion to apex, it was $3.48 \mathrm{~s}$ and $3.57 \mathrm{~s}$, respectively. These data suggest that the time windows used by previous researchers who failed to show that expressions occurred in emotionally evocative contexts (Ruiz-Belda et al., 2003) were too short to allow for

Table 3

Mean Time (in Seconds) From Match End to Expression Onset, Expression Onset to Expression Apex, and Match End to Expression Apex

\begin{tabular}{lccc}
\hline Place finish & $\begin{array}{c}\text { Match end to } \\
\text { expression onset }\end{array}$ & $\begin{array}{c}\text { Expression onset to } \\
\text { expression apex }\end{array}$ & $\begin{array}{c}\text { Match end to } \\
\text { expression apex }\end{array}$ \\
\hline Gold & 2.90 & 0.58 & 3.48 \\
Silver & 7.33 & 1.63 & 8.96 \\
Bronze & 2.57 & 1.00 & 3.57 \\
Fifth & 6.14 & 2.40 & 8.54 \\
\hline
\end{tabular}


the expressions to occur in the first place (under $2 \mathrm{~s}$ after stimulus). That these same researchers demonstrated that most expressions occurred in the first 2-s window of the subsequent phase of analysis is congruent with our data, as that would be the normal time for expressions to unfold anyway.

\section{How Did Expressive Behavior Differ During the Medal Ceremonies?}

Receiving the medal. As expected, 54 of the 56 athletes who participated in the medal ceremonies smiled when they received their medal $(z=6.95, p<.0001)$. However, when the specific type of smile was differentiated, differences emerged according to place finish. All 14 gold medalists displayed Duchenne smiles, 12 of them with the open mouth $(z=2.67, p<.01)$. Only 6 of the 14 silver medalists displayed Duchenne smiles by themselves or with the open mouth. Three displayed controlled Duchenne smiles (described more fully subsequently). One silver medalist displayed a non-Duchenne smile, and 1 displayed a controlled, nonDuchenne smile. Two displayed smile-sadness blends, and 1 displayed nothing.

Because facial actions related to control were prominent in the medal ceremonies, we describe them in more detail here. Behaviorally, these were smiles that co-occurred with buccinator (AU 14), sometimes in combination with mentalis and/or orbicularis oris (AUs 17 and 24). These lower face actions give the appearance that the expresser is making a conscious effort to control their facial behaviors and/or words, as if they are "biting their lip." That they often occurred with both Duchenne and non-Duchenne smiles suggested that these facial actions qualified the meaning of the smile, adding information to the message of the smile beyond the signal of enjoyment.

The bronze medalists' data were also revealing. Twenty of the 28 athletes displayed the open-mouth version of the Duchenne smile $(z=2.27, p<.05)$. Three displayed Duchenne smiles by themselves, 3 displayed controlled Duchenne smiles, 1 displayed a controlled, non-Duchenne smile, and 1 displayed contempt.

Collapsing the data demonstrated differences as a function of medal (see Table 2). Gold and bronze medalists were much more likely to display Duchenne smiles, and especially uncontrolled Duchenne smiles, than were silver medalists. These same findings occurred when only the silver and bronze medalists' data were compared against each other. These data provide behavioral evidence for the judgment data originally reported by Medvec et al. (1995). The silver medalists indeed did not display felt, enjoyable emotions as much as either the gold or the bronze medalists.

We tested for cultural differences in these expressions using the country classification described earlier and computing chi-square values on the 2 three-way contingency tables in the middle of Table 2. Neither was significant: all Duchenne versus all other expressions, $\chi^{2}(4, N=56)=0.90, n s$; all uncontrolled Duchenne smiles versus all other expressions, $\chi^{2}(4, N=56)=0.35, n s$. Thus there were no cultural differences in smiling behavior when athletes received their medals.

Podium posing. The athletes' expressions when they posed on the podium were also revealing. Fifty of the 56 athletes displayed some kind of smile, but when the specific type of smile was examined, differences emerged. All of the gold medalists smiled; 13 of 14 were Duchenne smiles $(z=3.21$, $p<.01$ ), and 9 of these were the open-mouth version. In contrast, only 9 of the 14 silver medalists smiled, and only 5 of these were uncontrolled. Three were controlled Duchenne smiles, 1 was a non-Duchenne smile, and 1 was a smile-sadness blend. Two of the silver medalists displayed sadness, 1 contempt, and 1 an uninterpretable expression. Twenty-six of the 28 bronze medalists smiled; 13 of these were open-mouth Duchenne smiles, 2 were Duchenne smiles by themselves, 6 were controlled Duchenne smiles, 4 were controlled nonDuchenne smiles, and 1 was a non-Duchenne smile.

Comparisons of the medalists' expressions (see Table 2) demonstrated again that the gold and bronze medalists were more likely to display Duchenne smiles and uncontrolled Duchenne smiles. Silver medalists were more likely to display negative or uninterpretable emotions. These data also provided behavioral evidence for the data reported by Medvec et al. (1995).

We tested for cultural differences in these expressions using the country classification described earlier and computed chi-square values on the 3 three-way contingency tables on the data in the bottom of Table 2. The chi-square for all Duchenne smiles versus all other expressions was significant, $\chi^{2}(4, N=56)=14.71, p<$ .01. Follow-up analyses revealed that gold and bronze medalists from North America-Western Europe and East Asia were much more likely to display Duchenne smiles (96\%) than all other expressions, whereas gold and bronze medalists from other countries were more likely to display other expressions, particularly non-Duchenne smiles (47\%), than Duchenne smiles. The threeway chi-square values for the other two analyses were both nonsignificant.

The data from both points of the medal ceremonies suggested that, despite the fact that the overwhelming majority of athletes smiled, in reality there were differences in their smiles, and those differences may have been reliably related to different expressions displayed at match completion. To test this idea, we crosstabulated whether or not the athletes displayed Duchenne smiles at the end of the match with whether or not they displayed Duchenne smiles during the medal ceremonies (see Table 4). Those who showed signs of genuinely enjoyable emotions at the end of the match were more likely to show those same signs of enjoyable emotions when they received the medal and posed on the podium. Conversely, those who did not display signs of enjoyable emotions at the end of the match were likely to not display such signs during the medal ceremonies, despite the fact that most athletes smiled. The same findings occurred when Duchenne smiles were differentiated according to whether or not they were accompanied by facial signs of control.

\section{Discussion}

This study produced provocative findings about facial expressions of emotion in emotionally charged, naturalistic situations; however, it was not conducted without limitations. First, we did not obtain self-reports of experience because it was logistically impossible. Although we have been careful to focus on the link between emotionally evocative situations and expressive behavior, and although we believe that the expressions are themselves tied to powerful emotional states in the athletes, our data cannot be used to make claims about the relationship between expression and experiences. Second, we used only one photographer, who was 
Table 4

Cross-Tabulation of the Expressions Produced at Match Completion With Expressions Produced When Athletes Received Their Medals

\begin{tabular}{|c|c|c|c|c|c|c|c|c|}
\hline \multirow[b]{2}{*}{ Occasion } & \multirow[b]{2}{*}{ Type of expression } & \multicolumn{2}{|c|}{ End of match } & \multirow[b]{2}{*}{$x^{2}$} & \multirow[b]{2}{*}{$d f$} & \multirow[b]{2}{*}{$p$} & \multirow[b]{2}{*}{ Odds ratio } & \multirow[b]{2}{*}{$R$} \\
\hline & & $\begin{array}{c}\text { Any } \\
\text { Duchenne } \\
\text { smiles }\end{array}$ & $\begin{array}{l}\text { All other } \\
\text { expressions }\end{array}$ & & & & & \\
\hline \multirow[t]{3}{*}{ Receipt of medal } & Any Duchenne smiles & 27 & 22 & 7.45 & 1 & .0063 & $\mathrm{n} / \mathrm{a}$ & .37 \\
\hline & All other expressions & 0 & 7 & & & & & \\
\hline & & $\begin{array}{c}\text { Uncontrolled } \\
\text { Duchenne } \\
\text { smiles }\end{array}$ & $\begin{array}{l}\text { All other } \\
\text { expressions }\end{array}$ & $x^{2}$ & $d f$ & $p$ & Odds ratio & $R$ \\
\hline \multirow[t]{3}{*}{ Receipt of medal } & Uncontrolled & & & & & & & \\
\hline & $\begin{array}{l}\text { Duchenne smiles } \\
\text { All other expressions }\end{array}$ & $\begin{array}{c}25 \\
2\end{array}$ & $\begin{array}{l}18 \\
11\end{array}$ & 7.31 & 1 & .0068 & 7.64 & .36 \\
\hline & & $\begin{array}{l}\text { Any } \\
\text { Duchenne } \\
\text { smiles }\end{array}$ & $\begin{array}{l}\text { All other } \\
\text { expressions }\end{array}$ & $\chi^{2}$ & $d f$ & $p$ & Odds ratio & $r$ \\
\hline \multirow[t]{3}{*}{ On the podium } & Any Duchenne smiles & 23 & 19 & 2.885 & 1 & .0894 & 3.03 & .23 \\
\hline & All other expressions & 4 & 10 & & & & & \\
\hline & & $\begin{array}{c}\text { Uncontrolled } \\
\text { Duchenne } \\
\text { smiles }\end{array}$ & $\begin{array}{l}\text { All other } \\
\text { expressions }\end{array}$ & $x^{2}$ & $d f$ & $p$ & Odds ratio & $r$ \\
\hline \multirow[t]{2}{*}{ On the podium } & Uncontrolled & & & 6.103 & 1 & 0134 & 405 & 33 \\
\hline & All other expressions & 7 & 17 & 0.103 & & .0154 & & .55 \\
\hline
\end{tabular}

situated in the middle of the two competition areas. This severely limited the photos to be analyzed, because he could only focus on 1 athlete at a time. (This was less a problem for the gold medal matches, which occurred one at a time.) Also, the dynamic nature of the competition precluded us from capturing expressions that may have occurred when athletes were facing away from the camera. For these reasons we have probably underestimated the expressions that did occur.

\section{Do Expressions Occur in Emotionally Evocative Contexts in Naturalistic Settings That Should Elicit Strong Emotions?}

Yes. Eighty-six percent of the athletes provided an expression at match completion (within 2.5-3 s after stimulus onset for the gold and bronze medalists), and the EMFACS dictionary characterized $97.46 \%$ of them, producing predictions for a wide range of emotion, including contempt, disgust, fear, sadness, and multiple types of smiles. The expressions corresponded to those reported previously by Ekman (Ekman, 1972; Ekman \& Friesen, 1971; Ekman et al., 1972, 1969) and others (reviewed earlier), in Ekman and Friesen's (1975) Unmasking the Face, in their stimulus set Pictures of Facial Affect (Ekman \& Friesen, 1976), and in Matsumoto and Ekman's (1988) Japanese and Caucasian Facial Expressions of Emotion (JACFEE) set. That there were no cultural differences in the first expressions at match completion is supportive of the universality of these expressions to occur when emotion is aroused. These results are in contrast to the findings of previous field studies reporting nonfindings (Fernandez-Dols \& Ruiz-Belda, 1995; Fernandez-Dols, Sanchez, Carrera, \& Ruiz-Belda, 1997; Kraut \& Johnson, 1979; Ruiz-Belda et al., 2003). We contend that the methodology we used corrected methodological limitations of the previous studies.

Some may argue that the expressions were produced because the athletes were in a social situation. Indeed, the athletes were competing against each other, being judged by referees, on center stage in a packed auditorium, and on television. In addition, athletes compete under the rules of competition, which regulate specific actions that can and cannot occur. Thus the event has many social ties, and athletes need to internalize many social conventions that affect behavior, even with minimal conscious awareness.

We argue, however, that these factors probably did not affect the very first expressions displayed at match completion (which are the ones we analyzed) for a number of reasons. The Olympic Games is the pinnacle of sport competition, and Olympic athletes compete in the most intense matches of their lives, and perhaps for the only times in their lives. Judo is combat, and competition requires tremendous concentration and focus, because athletes struggle to throw, pin, strangle, or apply joint locks to each other. Each match requires extraordinary strength and conditioning, as athletes' hearts have been clocked at 200 beats per minute. Being in a medal match means that the athletes have won numerous matches earlier in the day, and by the time they are in the medal match they are at the edge of physical and mental exhaustion, in the most important match of 
their lives, in the most exciting and important sporting event in the world.

Moreover, because instant wins can occur at any time during a judo match, outcomes are never decided until the very end, no matter how much of a lead an athlete has. Our main analyses used the very first expressions produced, which began 2.5 to $3 \mathrm{~s}$ after match completion, and were thus the very first reactions of the athletes. The setup precluded us from obtaining expressions when athletes faced the crowd, because the photographer was opposite the crowd and main television cameras, and most expressions occurred before the athlete turned to face the crowd. Finally, $72 \%$ of the coded expressions occurred when the athletes were not directly facing anyone.

For these reasons we contend that, at the precise moment when matches were completed and outcomes determined, athletes' initial expressions probably were not produced because of the social nature of the event. After having been engaged in combat in the most important match of their lives, the athletes' expressions were probably reflections of their emotional reactions to the outcome of the match, relatively unaffected by the social nature of the event (although there is an interesting possibility that the intensity of the expressions differed depending on whether the athlete was socially engaged or not; this should be followed in future studies). Combat is a social event, but the expressions occurred not because combat is a social event but because of the results of that combat. That they occurred within a social event is not surprising because emotions evolved to deal with social events of great import. Emotions and expression can, however, of course occur when alone as well, but there is little question that battle is a social event that elicits strong emotional responses, just as birth and seduction.

Although we did not analyze the second, third, or fourth expressions after match completion because of statistical independence issues and small sample size, they provide cues about how social convention may have influenced expression soon after the athletes' initial reactions. One of the gold medalists, for instance, produced a large Duchenne smile immediately when he threw his opponent for an instant win (AUs $6 \mathrm{E}+12 \mathrm{E}+25$ ), 1 s after the referee announced the score, and while he was facing away from the crowd. Three s later, however, after he got up and before the match was awarded, he controlled his large smile by pushing his lower lip up, tightening the corners of his lips, and rolling his lips together (AUs $6 \mathrm{C}+12 \mathrm{C}+14 \mathrm{~B}+17 \mathrm{~B}+28 \mathrm{~B})$. One s after that he again produced a Duchenne smile without the control, which lasted for several seconds. Then $10 \mathrm{~s}$ after that he again produced the Duchenne smile with the control.

Another way in which expressions changed over the course of a few seconds was when initial smiling faces were transformed to blends of happiness and sadness. These occurred only in individuals who won their medal match (1 gold medalist and 8 bronze medalists). In these cases these blended expressions occurred after an athlete's initial smile, where the athlete began to show sadnessdistress in addition to the smile as he or she began to cry. Although there are several theories that account for such crying when happy (Frijda, 2001; Scheff, 1979; Vingerhoets \& Cornelius, 2000), we believe that one way to understand this phenomenon in the context of achievement is related to the display rule of not showing one's sadness or distress if one loses (i.e., being a good loser). That is, both athletes probably felt distressed about the impending outcome of the match and the possibility that they might lose. For winners, however, this display rule is lifted once the outcome is determined, and thus it becomes more appropriate for them to display their distress. (A different display rule that exists, however-namely, to be a good winner and not boast-would explain why some victorious athletes also curb their expressions of joy as described earlier.) For athletes who lose their final match, however, the display rule remains. Blended expressions of happiness and sadness did occur in the silver medalists, in fact, but only during the medal ceremonies. These probably reflected either the athlete's simultaneous and genuine joy of accomplishment and the sadness of having lost the final match, or sadness of having lost the final match qualified by a smile.

\section{The Facial Signs of Victory and Defeat}

The facial signs of victory were Duchenne smiles and, in particular, the open-mouth version of the Duchenne smile. These data provide further support for the view that Duchenne smiles are associated with enjoyable emotions (Ekman et al., 1990; Frank et al., 1993; Hess et al., 1995; Keltner \& Bonanno, 1997; Smith, 1995). Because no other expression was as dominant among the victors, the data also suggest that the Duchenne smile may be the only facial marker of different types of enjoyable emotions (Ekman, 2003), including fiero - the joy of victory.

There is probably evolutionary reason why this may be so. Facial behaviors provide rapid, reliable communication of emotional states to others, and it may not have been as adaptively necessary to communicate different enjoyable emotions to others immediately and from a distance as it was to communicate differentiated negative emotions such as anger, disgust, or fear. Enjoyable emotions do not represent immediate threats to survival; when one is threatened, however, it is important to know whether to run or attack. Future research will need to examine whether other channels communicate distinctly different enjoyable emotions. Ekman (2003) suggested that the voice may differentiate enjoyable emotions. Tracy and Robins (2004) indicated that pride is associated with direct eye contact; Duchenne smiles; an open, expanded, body posture; and hand or hands above the head or on the hips.

The expressions of the defeated athletes were strikingly different. Of the 42 athletes who lost their medal match, only 1 smiled; the others showed a variety of negative emotions, including sadness, contempt, disgust, and fear. Moreover, a not insubstantial number of them also displayed no emotion. That they did not simply show less smiling strongly suggests that their emotional experiences were substantially different than those of the gold and bronze medalists; thus, there is not a linear decrease in smiling from gold, silver, and bronze medalists.

Of course winning a silver medal at the Olympic Games should be a cause for joy in anyone. Thus, it is interesting that silver medalists (and fifth placers) did not smile. In fact, there are several reasons why this might have occurred. First, all athletes at this level of competition are intense competitors who do not like to lose. They were probably extremely disappointed by the fact that they lost their match, which leaves a bittersweet aftertaste when competition is completed. Thus, they probably did not smile because losing is not enjoyable.

Because we did not obtain self-reports of subjective experience from the athletes, we can only speculate about why they displayed the various negative emotions they did. One explanation might be 
that the expressions of sadness, contempt, disgust, and fear all signal a single, undifferentiated, negatively valenced emotional state (Russell et al., 2003; Russell \& Feldman Barrett, 1999). We do not, however, agree with this possibility, because it is unclear as to why the same antecedent (losing the match) and the same supposed emotional reaction (an undifferentiated negative one) would lead to uniquely different expressions, regardless of what label EMFACS might call it. Instead, we believe that losing the match was appraised in different ways that led to different emotional reactions, which, in turn, led to discretely different emotion signals. There are several ways this can occur. For instance, countries differ considerably in the pressure placed on athletes to win Olympic medals. In some countries, the difference between gold and silver can mean the difference between a life of comfort or not, stardom or not, and making a living or not. Moreover, there are many prior expectations coming into the games. Winners of the previous year's world championships, for example, are often considered favorites to win Olympic gold. When they do not, they may not be as joyful with a silver or a bronze medal, despite the fact that obtaining a silver or a bronze medal at the Olympic Games is a tremendous achievement. Both silver medalists who displayed contempt, for example, and the lone bronze medalist, were previous world champions who came to the Olympics as gold medal favorites and who might have appraised the situation as one in which they were superior to the winner despite the loss.

A not insubstantial number of silver medalists and fifth placers displayed nothing on their faces or displayed expressions that were not interpretable. We believe that this finding is related to the display rule for athletes to "be a good loser." This interpretation is bolstered by the fact that all of these expressions involved relatively strong, bilateral buccinator activity (AU 14), oftentimes with lower lip raise (AU 17) and lip press (AU 24). This same muscle action (AU 14) denoted controlled smiling. And these expressions occurred later than the initial reactions (see Table 4), which, as we discussed earlier, probably allowed time for display rules and social conventions to begin influencing expression more. We believe that these expressions occurred because the athletes were controlling their facial displays so as to not signal their disappointment at having lost the match. Tomkins (1978) suggested that such lower face facial actions signal backed-up affect. When occurring with anger, Tomkins (1978) suggested that these facial actions evolved to prevent angry individuals from biting and attacking others.

We speculate, therefore, that there is no unique face of defeat. Instead, athletes appraise losses in individual ways, some eliciting sadness and distress from not obtaining their goal of winning, others being superior over their opponents, others being disgusted at the opponent or the result, and others still being fearful of the consequences of having lost. In addition, there may be individual differences in expressivity that may have influenced these expressions (Gross \& John, 1995; King \& Emmons, 1990; Kring, Smith, $\&$ Neale, 1994), as well as those of the victors (e.g., differentiating between those who continuously smile with or without controls vs. those who smile and then cry). Differences in the meaning and thus appraisals of the loss for each of the athletes, therefore, bring about different emotional reactions, which elicit different expressions (Brown \& Dutton, 1995).

\section{How Much Time Elapses From the Occurrence of an Emotion-Eliciting Stimulus to Its Expressive Reaction?}

The expressions began between 2 and $3 \mathrm{~s}$ after the eliciting stimulus occurred and reached apex within 3 and 4 s. These findings explain why Ruiz-Belda et al. (2003) did not find expressions in the solitary conditions of their experiment; the time frame they examined (1.35 s from stimulus occurrence) was not long enough to allow for expressions to unfold in reaction to the antecedent event. In fact, their data demonstrated that most smiles occurred within $4 \mathrm{~s}$ of the antecedent, which is congruent with our data.

These data open the door to studies of how emotional reactions are activated. Expressive behaviors in the face are one component of the emotion package, and different components may have different timing features. Stepping onto a curb and perceiving a bus coming at you at the last minute would elicit almost immediate (certainly less than $2.5 \mathrm{~s}$ ) motor response to get out of the way, suggesting that the motor response system has a different timing characteristic than the face. These motor responses, in turn, probably have different timings than cognitions and physiology. It is also possible that these timing characteristics differ by emotion and context. Fear may produce relatively quick reactions; enjoyable emotions may produce relatively longer ones.

Moreover there is probably a large moderating role of the contents of activated states of the mind when emotion is aroused. The athletes in our study were engaged in intense combat until match completion. When the match finally ended, athletes needed to switch from "combat mode" to a mode in which they could process and evaluate the results. When an individual is in a comedy club with friends, however, and has been repeatedly laughing at jokes, the time from stimulus occurrence (the next joke) to expression may be considerably shorter because the already activated network makes it easier for such emotions to be elicited and expressed. Future studies can examine how different activated states of mind may moderate the timing of emotional responses, and the differences among different types of responses.

\section{The Effects of Social Situation on Expressive Behavior}

Nearly all athletes spontaneously smiled during both periods of the medal ceremonies, probably because of the highly staged and public nature of the ceremonies. Here, athletes have had time to process the results of their performance, need to interact with dignitaries, and are pressured to put on a good face for the crowd and television. That this was true for the silver medalists, especially given the fact that none of them had smiled at match completion and nearly all had displayed a negative expression or no expression, demonstrates the powerful influence of social context on expressive behavior.

However, the smiles of the silver medalists were differentiated from the smiles of the gold and the bronze medalists. Gold and bronze medalists displayed Duchenne smiles, whereas silver medalists were more likely to display controlled Duchenne smiles, non-Duchenne smiles, or smiles blended with sadness. On the podium, after receiving the medal and after the national anthem of the gold medalist was played, some silver medalists did not smile at all, instead displaying contempt, sadness, or uninterpretable expressions. These data suggested that, although the silver med- 
alists attempted to be socially appropriate by smiling during the medal ceremonies, they probably did not experience solely enjoyable emotions. Instead they were probably either experiencing negative emotions and masking or qualifying them with smiles or were experiencing blends of enjoyable and negative emotions. One of these might be regret, which would be commensurate with the findings of Medvec et al. (1995).

It is interesting that it is only on the podium that cultural differences in expression were observed. The fact that cultural differences emerged here and not immediately at match completion nor while interacting with the dignitary is probably due to the fact that the effects of context were too powerful in these latter situations to allow for cultural differences to emerge. At match completion, the initial expressions were probably largely determined by the athlete's strong emotional reactions to the outcomes. When athletes were interacting with the dignitary, their expressions were probably largely determined by the fact that they were in a highly public situation and were interacting with a dignitary. On the podium, however, the pressure of the medal ceremonies and interacting with the dignitary was lifted, loosening the power of context to override culture and allowing some cultural differences to occur.

However, our data cannot speak to what aspect of culture produced the differences. There were no differences between North Americans-Western Europeans and East Asians, thus ruling out a simple individualism versus collectivism interpretation. Future studies will need to examine more specifically what aspects of culture helped to produce these, and other, cultural differences in spontaneous expressions.

\section{References}

Berenbaum, H., \& Oltmanns, T. (1992). Emotional experience and expression in schizophrenia and depression. Journal of Abnormal Psychology, 101, 37-44.

Bonanno, G. A., \& Keltner, D. (2004). The coherence of emotion systems: Comparing "on-line" measures of appraisal and facial expressions, and self-report. Cognition \& Emotion, 18, 431-444.

Brown, J. D., \& Dutton, K. A. (1995). The thrill of victory, the complexity of defeat: Self-esteem and people's emotional reactions to success and failure. Journal of Personality and Social Psychology, 68, 712-722.

Camras, L. A., Oster, H., Campos, J., Miyake, K., \& Bradshaw, D. (1992). Japanese and American infants' responses to arm restraint. Developmental Psychology, 28, 578-583.

Charlesworth, W. R., \& Kreutzer, M. A. (1973). Facial expressions of infants and children. In P. Ekman (Ed.), Darwin and facial expression (pp. 91-168). New York: Academic Press.

Chesney, M. A., Ekman, P., Friesen, W. V., Black, G. W., \& Hecker, M. H. (1990). Type A behavior pattern: Facial behavior and speech components. Psychosomatic Medicine, 52, 307-319.

Chevalier-Skolnikoff, S. (1973). Facial expression of emotion in nonhuman primates. In P. Ekman (Ed.), Darwin and facial expression (pp. 11-89). New York: Academic Press.

Darwin, C. (1998). The expression of emotion in man and animals. New York: Oxford University Press. (Original work published 1872)

Davidson, R. J. (2003). Parsing the subcomponents of emotion and disorders of emotion: Perspectives from affective neuroscience. In R. J. Davidson, K. R. Scherer, \& H. H. Goldsmith (Eds.), Handbook of affective sciences (pp. 8-24). New York: Oxford University Press.

Ekman, P. (1972). Universal and cultural differences in facial expression of emotion. In J. R. Cole (Ed.), Nebraska Symposium on Motivation (pp. 207-283). Lincoln: University of Nebraska Press.
Ekman, P. (1992). Are there basic emotions? Psychological Review, 99, $550-553$.

Ekman, P. (1994). Strong evidence for universals in facial expressions: A reply to Russell's mistaken critique. Psychological Bulletin, 115, 268 287.

Ekman, P. (1999). Basic emotions. In T. D. A. T. Power (Ed.), The handbook of cognition and emotion (pp. 45-60). Sussex, England: John Wiley.

Ekman, P. (2003). Emotions revealed. New York: Times Books.

Ekman, P., Davidson, R. J., \& Friesen, W. V. (1990). The Duchenne smile: Emotional expression and brain physiology: II. Journal of Personality and Social Psychology, 58, 342-353.

Ekman, P., \& Friesen, W. (1969). The repertoire of nonverbal behavior: Categories, origins, usage, and coding. Semiotica, 1, 49-98.

Ekman, P., \& Friesen, W. (1971). Constants across culture in the face and emotion. Journal of Personality and Social Psychology, 17, 124-129.

Ekman, P., \& Friesen, W. V. (1975). Unmasking the face: A guide to recognizing emotions from facial clues. Englewood Cliffs, NJ: Prentice Hall.

Ekman, P., \& Friesen, W. (1976). Pictures of facial affect. Palo Alto, CA: Consulting Psychologists Press.

Ekman, P., \& Friesen, W. V. (1978). Facial action coding system: Investigator's guide. Palo Alto, CA: Consulting Psychologists Press.

Ekman, P., \& Friesen, W. (1982a). EMFACS. Unpublished manuscript.

Ekman, P., \& Friesen, W. V. (1982b). Felt, false, and miserable smiles. Journal of Nonverbal Behavior, 6, 238-258.

Ekman, P., Friesen, W., \& Ancoli, S. (1980). Facial signs of emotional experience. Journal of Personality and Social Psychology, 39, 11251134.

Ekman, P., Friesen, W. V., \& Ellsworth, P. (1972). Emotion in the human face: Guidelines for research and an integration of findings. New York: Pergamon Press.

Ekman, P., Friesen, W. V., \& O'Sullivan, M. (1988). Smiles when lying. Journal of Personality and Social Psychology, 54, 414-420.

Ekman, P., Friesen, W. V., \& Simons, R. C. (1985). Is the startle reaction an emotion? Journal of Personality and Social Psychology, 49, 14161426.

Ekman, P., Levenson, R. W., \& Friesen, W. V. (1983, September 16). Autonomic nervous system activity distinguishes among emotions. Science, 221, 1208-1210.

Ekman, P., Matsumoto, D., \& Friesen, W. (1997). Facial expression in affective disorders. In P. Ekman \& E. L. Rosenberg (Eds.), What the face reveals: Basic and applied studies of spontaneous expression using the facial action coding system (FACS) (pp. 331-341). New York: Oxford University Press.

Ekman, P., Sorenson, E. R., \& Friesen, W. V. (1969, April 4). Pancultural elements in facial displays of emotion. Science, 164, 86-88.

Elfenbein, H. A., \& Ambady, N. (2002). On the universality and cultural specificity of emotion recognition: A meta-analysis. Psychological Bulletin, 128, 205-235.

Ellgring, H. (1986). Nonverbal expression of psychological states in psychiatric patients. European Archives of Psychiatry and Neurological Sciences, 236, 31-34.

Fernandez-Dols, J. M., \& Ruiz-Belda, M. A. (1995). Are smiles signs of happiness? Gold medal winners at the Olympic Games. Journal of Personality and Social Psychology, 69, 1113-1119.

Fernandez-Dols, J. M., Sanchez, F., Carrera, P., \& Ruiz-Belda, M.-A. (1997). Are spontaneous expressions and emotions linked? An experimental test of coherence. Journal of Nonverbal Behavior, 21, 163-177.

Frank, M. G., \& Ekman, P. (1993). Not all smiles are created equal: The differences between enjoyment and nonenjoyment smiles. Humor: International Journal of Humor Research, 6, 9-26.

Frank, M. G., Ekman, P., \& Friesen, W. V. (1993). Behavioral markers and 
recognizability of the smile of enjoyment. Journal of Personality and Social Psychology, 64, 83-93.

Fridlund, A. (1994). Human facial expression: An evolutionary view. San Diego, CA: Academic Press.

Fridlund, A. (1997). The new ethology of human facial expressions. In J. A. Russell \& J. M. Fernandez-Dols (Eds.), The psychology of facial expression (pp. 102-129). Cambridge, England: Cambridge University Press.

Fridlund, A. (2002). The behavioral ecology view of smiling and other facial expressions. In M. Abel (Ed.), An empirical reflection on the smile (Vol. 4, pp. 45-82). Lewiston, NY: Edwin Mellen Press.

Frijda, N. H. (2001). Foreward. In A. J. J. M. Vingerhoets \& R. R. Cornelius (Eds.), Adult crying: A biopsychosocial approach (pp. xiiixviii). Hove, England: Brunner-Routledge.

Geen, T. (1992). Facial expressions in socially isolated nonhuman primates: Open and closed programs for expressive behavior. Journal of Research in Personality, 26, 273-280.

Goffman, E. (1959). The presentation of self in everyday life. Oxford, England: Doubleday.

Gosselin, P., Kirouac, G., \& Dore, F. (1995). Components and recognition of facial expression in the communication of emotion by actors. Journal of Personality and Social Psychology, 68, 83-96.

Gross, J. J., \& John, O. P. (1995). Facets of emotional expressivity: Three self-report factors and their correlates. Personality \& Individual Differences, 19, 558-568.

Hauser, M. (1993, July 23). Right hemisphere dominance for the production of facial expression in monkeys. Science, 261, 475-477.

Heller, M., \& Haynal, V. (1994). Depression and suicide faces. Cahiers Psychiatriques Genevois, 16, 107-117.

Hess, U., Banse, R., \& Kappas, A. (1995). The intensity of facial expression is determined by underlying affective states and social situations. Journal of Personality and Social Psychology, 69, 280-288.

Hess, U., \& Kleck, R. E. (1990). Differentiating emotion elicited and deliberate emotional facial expressions. European Journal of Social Psychology, 20, 369-385.

Hofstede, G. H. (2001). Culture's consequences: Comparing values, behaviors, institutions and organizations across nations ( $2 \mathrm{nd}$ ed.). Thousand Oaks, CA: Sage.

Izard, C. E. (1994). Innate and universal facial expressions: Evidence from developmental and cross-cultural research. Psychological Bulletin, 115, 288-299.

Keltner, D. (1995). The signs of appeasement: Evidence for the distinct displays of embarrassment, amusement, and shame. Journal of Personality and Social Psychology, 68, 441-454.

Keltner, D., \& Bonanno, G. A. (1997). A study of laughter and dissociation: The distinct correlates of laughter and smiling during bereavement. Journal of Personality and Social Psychology, 73, 687-702.

Keltner, D., Ekman, P., Gonzaga, G. C., \& Beer, J. (2003). Facial expressions of emotion. In R. J. Davidson, K. G. Scherer, \& H. H. Goldsmith (Eds.), Handbook of affective sciences (pp. 415-432). New York: Oxford University Press.

Keltner, D., Moffitt, T., \& Stouthamer-Loeber, M. (1995). Facial expressions of emotion and psychopathology in adolescent boys. Journal of Abnormal Psychology, 104, 644-652.

Kerr, J. H., Wilson, G. V., \& Nakamura, I. (2005). Emotional dynamics of soccer fans at winning and losing games. Personality \& Individual Differences, 38, 1855-1866.

King, L. A., \& Emmons, R. A. (1990). Conflict over emotional expression: Psychological and physical correlates. Journal of Personality and Social Psychology, 58, 864-877.

Kraut, R. E., \& Johnson, R. E. (1979). Social and emotional messages of smiling: An ethological approach. Journal of Personality and Social Psychology, 37, 1539-1553.

Kring, A. M., Smith, D. A., \& Neale, J. M. (1994). Individual differences in dispositional expressiveness: Development and validation of the emotional expressivity scale. Journal of Personality and Social Psychology, 66, 934-949.

Leonard, C. M., Voeller, K. K. S., \& Kudau, J. M. (1991). When's a smile a smile? Or how to detect a message by digitizing the signal. Psychological Science, 2, 166-172.

Levenson, R. W. (2005). FACS/EMFACS emotion predictions [Computer software]. Berkeley: University of California, Department of Psychology.

Levenson, R. W., Carstensen, L. L., Friesen, W. V., \& Ekman, P. (1991). Emotion, physiology, and expression in old age. Psychology and Aging, 6, 28-35.

Levenson, R. W., Ekman, P., \& Friesen, W. V. (1990). Voluntary facial action generates emotion-specific autonomic nervous system activity. Psychophysiology, 27, 363-384.

Levenson, R. W., Ekman, P., Heider, K., \& Friesen, W. V. (1992). Emotion and autonomic nervous system activity in the Minangkabau of West Sumatra. Journal of Personality and Social Psychology, 62, 972-988.

Matsumoto, D. (2001). Culture and emotion. In D. Matsumoto (Ed.), The handbook of culture and psychology (pp. 171-194). New York: Oxford University Press.

Matsumoto, D., \& Ekman, P. (1988). Japanese and Caucasian facial expressions of emotion and neutral faces (jacfee and jacneuf). Retrieved from http://www.paulekman.com

Matsumoto, D., Ekman, P., \& Fridlund, A. (1991). Analyzing nonverbal behavior. In P. W. Dowrick (Ed.), Practical guide to using video in the behavioral sciences (pp. 153-165). New York: Wiley.

Matsumoto, D., Haan, N., Gary, Y., Theodorou, P., \& Cooke-Carney, C. (1986). Preschoolers' moral actions and emotions in prisoner's dilemma. Developmental Psychology, 22, 663-670.

Matsumoto, D., \& Kupperbusch, C. (2001). Idiocentric and allocentric differences in emotional expression and experience. Asian Journal of Social Psychology, 4, 113-131.

Medvec, V. H., Madey, S. F., \& Gilovich, T. (1995). When less is more: Counterfactual thinking and satisfaction among Olympic medalists. Journal of Personality and Social Psychology, 69, 603-610.

Messinger, D. S., Fogel, A., \& Dickson, K. L. (2001). All smiles are positive, but some smiles are more positive than others. Developmental Psychology, 37, 642-653.

Richardson, C., Bowers, D., Bauer, R., Heilman, K., \& Leonard, C. M. (2000). Digitizing the moving face during dynamic displays of emotion. Neuropsychologia, 38, 1028-1039.

Romney, A. K., Moore, C. C., \& Rusch, C. D. (1997). Cultural universals: Measuring the semantic structure of emotion terms in English and Japanese. Proceedings of the National Academy of Sciences, USA, 94, $5489-5494$.

Rosenberg, E. L., \& Ekman, P. (1994). Coherence between expressive and experiential systems in emotion. Cognition \& Emotion, 8, 201-229.

Rosenberg, E. L., Ekman, P., \& Blumenthal, J. A. (1998). Facial expression and the affective component of cynical hostility in male coronary heart disease patients. Health Psychology, 17, 376-380.

Rosenberg, E. L., Ekman, P., Jiang, W., Babyak, M., Coleman, R. E., Hanson, M., et al. (2001). Linkages between facial expressions of anger and transient myocardial ischemia in men with coronary heart disease. Emotion, 1, 107-115.

Ruch, W. (1993). Extraversion, alcohol, and enjoyment. Personality \& Individual Differences, 16, 89-102.

Ruch, W. (1995). Will the real relationship between facial expression and affective experience stand up: The case of exhilaration. Cognition \& Emotion, 9, 33-58.

Ruiz-Belda, M. A., Fernandez-Dols, J. M., Carrera, P., \& Barchard, K. (2003). Spontaneous facial expressions of happy bowlers and soccer fans. Cognition \& Emotion, 17, 315-326. 
Russell, J. A. (1991). Culture and the categorization of emotions. Psychological Bulletin, 110, 426-450.

Russell, J. A. (1994). Is there universal recognition of emotion from facial expression? A review of cross-cultural studies. Psychological Bulletin, $115,102-141$.

Russell, J. A., Bachorowski, J.-A., \& Fernandez-Dols, J. M. (2003). Facial and vocal expressions of emotion. Annual Review of Psychology, 54, 329-349.

Russell, J. A., \& Feldman Barrett, L. (1999). Core affect, prototypical emotional episodes, and other things called emotion: Dissecting the elephant. Journal of Personality and Social Psychology, 76, 805-819.

Russell, J. A., \& Fernandez-Dols, J. M. (1997). The psychology of facial expressions. New York: Cambridge University Press.

Sayette, M., Wertz, J., Martin, C., Cohn, J., Perrott, M., \& Hobel, J. (2003). Effects of smoking opportunity on cue-elicited urge: A facial coding analysis. Experimental and Clinical Psychopharmacology, 11, 218-227.

Scheff, T. J. (1979). Catharsis in healing, ritual and drama. Berkeley: University of California Press.

Schmidt, K. L., Cohn, J. F., \& Tian, Y. (2003). Signal characteristics of spontaneous facial expressions: Automatic movement in social and solitary smiles. Biological Psychology, 65, 49-66.

Schwartz, S. H. (2004). Mapping and interpreting cultural differences around the world. In H. Vinken, J. Soeters, \& P. Ester (Eds.), Comparing cultures, dimensions of culture in a comparative perspective (pp. 4373). Leiden, The Netherlands: Brill.

Shaver, P. R., Murdaya, U., \& Fraley, R. C. (2001). The structure of the Indonesian emotion lexicon. Asian Journal of Social Psychology, 4, 201-224.

Shaver, P. R., Schwartz, J. C., Kirson, D., \& O’Connor, C. (1987). Emotion knowledge: Further exploration of a prototype approach. Journal of Personality and Social Psychology, 52, 1061-1086.
Smith, M. C. (1995). Facial expression in mild dementia of the Alzheimer type. Behavioural Neurology, 8, 149-156.

Snowdon, C. T. (2003). Expression of emotion in nonhuman animals. In R. J. Davidson, K. Scherer, \& H. H. Goldsmith (Eds.), Handbook of affective sciences (pp. 457-480). New York: Oxford University Press.

Soussignan, R. (2002). Duchenne smile, emotional experience, and autonomic reactivity: A test of the facial feedback hypothesis. Emotion, 2, $52-74$

Steimer-Krause, E., Karuse, R., \& Wagner, G. (1990). Interaction regulations used by schizophrenic and psychosomatic patients: Studies on facial behavior in dyadic interactions. Psychiatry, 53, 209-228.

Tomkins, S. S. (1962). Affect, imagery, and consciousness: Vol. 1. The positive affects. New York: Springer Publishing Company.

Tomkins, S. S. (1963). Affect, imagery, and consciousness: Vol. 2. The negative affects. New York: Springer Publishing Company.

Tomkins, S. S. (1978). Script theory: Differential magnification of affects. In Herbert E. Howe \& Richard A. Dienstbier (Eds.), Nebraska Symposium on Motivation (Vol. 26, pp. 201-236). Lincoln: University of Nebraska Press.

Tracy, J. L., \& Robins, R. W. (2004). Show your pride: Evidence for a discrete emotion expression. Psychological Science, 15, 104-197.

Tsai, J. L., \& Levenson, R. W. (1997). Cultural influences on emotional responding: Chinese American and European American dating couples during interpersonal conflict. Journal of Cross-Cultural Psychology, 28, $600-625$.

Vingerhoets, A. J. J. M., \& Cornelius, R. R. (2000). Adult crying: A model and review of the literature. Review of General Psychology, 4, 354-377.

Received March 11, 2005

Revision received February 13, 2006

Accepted March 21, 2006 